\title{
Towards an Adequate Framework for Academic Workspace Evaluation: How Academics are affected by Environments for Work
}

\author{
Adenipekun Martins Taiwo, Ajibola Mayowa Olusola, Oluwunmi Adedamola Olufunke
}

\begin{abstract}
This paper explores user-centred variables in academic work environments as it affects job performance with a view to generating holistically adequate Academic Workspace Evaluation (AWE) framework for universities. The paper considers the trends of evolutionary changes in academics in recent time, technological impact of emerging academic activities, shifting barriers in frontiers of knowledge-based work, utilisation of research findings beyond territorial limitations, and the need for standardisation of Academic Workspace. Consequently, a broad-review of literature on variables that underpins adequate academic workspace environments towards users-satisfaction for effective and productive work conduct is carried out. The paper identifies three basic units of academic work environments and the variables identified in each unit were grouped accordingly for ease of analysis: the organisation culture environment, the employees' work environment and the academic workspace environment. The academic workspace environment is made of two integral parts: the physical internal environmental condition and the furniture ergonomic comfort environment of the workspace. Differences in culture, ethics, system, process, modes and pattern of work operations, purpose and objectives between university organisations create difficulty to generating a holistic universal user-centred AWE framework. The framework is context-based designed to accommodate local contents within the conventional structure arrangement of respective universities. This will provide an adequate Academic Workspace Benchmark Standard (AWBS) for use in universities globally.
\end{abstract}

Index Terms- Academic Workspace Evaluation Framework, User-centred variables, Comfort Satisfaction, Effective Performance and Productivity.

\section{INTRODUCTION}

The The appropriacy of academic workspace environment is important in developing effective performance and improve organisational productivity in universities in the contemporary time. Casual interaction at workplace were in the past discouraged by employers because such was viewed as distraction from real work. Today, cooperation and innovation on the job promote interaction, particularly if design of work environment succinctly balance both physical and social factors of proximity, privacy and

Adenipekun, Martins Taiwo, Department of Estate Management College of Science and Technology, Covenant University, Ota, Nigeria Ajibola, Mayowa Olusola, Department of Estate Management College of Science and Technology, Covenant University, Ota, Nigeria Oluwunmi, Adedamola Olufunke, Department of Estate Management College of Science and Technology, Covenant University, Ota, Nigeria 08034743392 permission based on affordances [85]. Fluidity of academic activities in modern time learning, training and education has increased team work and the interaction required to encourage, promote innovation and creativity in knowledge-based work arising from interdisciplinary needs of knowledge exchange in industry and academia [86]. The decision to shaping the work experience of university organisation is presently due to new design caused by changing technology, complexity of workstyles, institutional cultures, struggle to create effective, adequate employee workspace environments for retention of employee, performance, satisfaction and lowering facilities costs [87]. Impact of change caused the difficulty in ascertaining the future with maximum precision leading to volatile and uncertain characteristics of the new millennium [27]. Complexity of workstyles created the idea of innovative workspace flexibility options in organisations [82]. For these and many other reasons, standardisation of academic workspace is contemporarily globally expedient [86]. AWE framework is conceived on four key theories that underlines operations in work environment. Firstly, the theory of organisation culture, secondly, the theory of healthy work environment, thirdly, the theory of workspace comfort and, lastly, the theory of knowledge-work in the changing world of work. In summary, the ability of university organisation to achieve its desired goal depends on how the three units of the work environment in universities can meet each of workspace requirements holistically and adequately. The review of literature is to explain this in detail.

\section{RESEARCH APPROACH}

This study applied a deductive reasoning approach by moving from theoretical ideology to generating a schematic relationship of the basic environments in academics, a model created was tested from the conceptual framework to form a conclusion. The simple model was proposed to knit together the various integra parts of the work environment using the relevant cognate theories. Review of previous studies was achieved from 289 publications consisting 33 Government white papers, 10 Conference papers, 110 Journal articles, 46 Textbooks, and 90 Miscellaneous sourced papers. These publications were derived from Springer, Google, Google Scholar, Research Gate, Emerald, Scopus, and Elsevier outlets. A total of 131 user-centred cognate variables were generated for AWE. 


\section{Towards an Adequate Framework for Academic Workspace Evaluation: How Academics are affected by Environments for Work}

\section{LITERATURE REVIEW}

Academic workspace is conceived as set of concentric circles with worker occupying an office, connected by walls, circulation, conveyors, lifts and other activities areas like the classrooms, workshops, studios, libraries, laboratories, seminar and conference halls, lecture theatres, hallways and elevators that leads to other work-groups. Academic workspace extends beyond the building envelope. It includes the circulation paths, the meeting rooms, the cafeteria, coffee station, and support spaces like the copier rooms, stairs, and the parking space [75][8]. Academic workspace is designed for learning, teaching, demonstration, research, and similar support services for common scholarly objective, and it is therefore taken as subset of the global university work environment and operates within distinct organizational structure, culture and ethics (See Fig.1).

The quality of academic work environment depends on factors like organisation culture, healthy work environment, open communication, work-life balance, training and development focus, strong team spirit, spirituality and wellbeing at work [7][24][5][70]. It includes aspect of the physical workspace design for future workforce, office location, services of mobile worker, technology [83] and some other important factors like the natural lighting quality, space shape dimensions, room temperature, space location, access and circulation within the room space, noise level, floor surface finishes, interior beauty, ventilation, room humidity, air quality, air freshness, and electric lighting comfort [17][55][77][78].

Conceptually, academic work environment transcends the broad category of the elements of physical setting alone like heat, temperature, lighting, and ventilation, characteristic of the job workload, task complexity, organization culture, history, ethics; and work-home relationship [17] [55]. It also includes the physical and psychological wellbeing of people. According to [6], work environment impact job performance of employees thereby leads to significant growth in user's satisfaction, efficiency and productivity. [20] [76] [10] and [77] added elements of glare, auditory distraction, drafts and furniture configuration to features for consideration in the assessment of work environment. According to [14], to achieve a functional work environment requires it must operate as system, process, structures, with a provision that gives opportunity for housing loan, car loan and other loan advances, staff development and other opportunities for personal initiatives for self-growth. However, [60], viewed work environment as a total sum of interrelationship between employee's factors that contend with employee's activities and the condition of work environment associated with employees' performance.

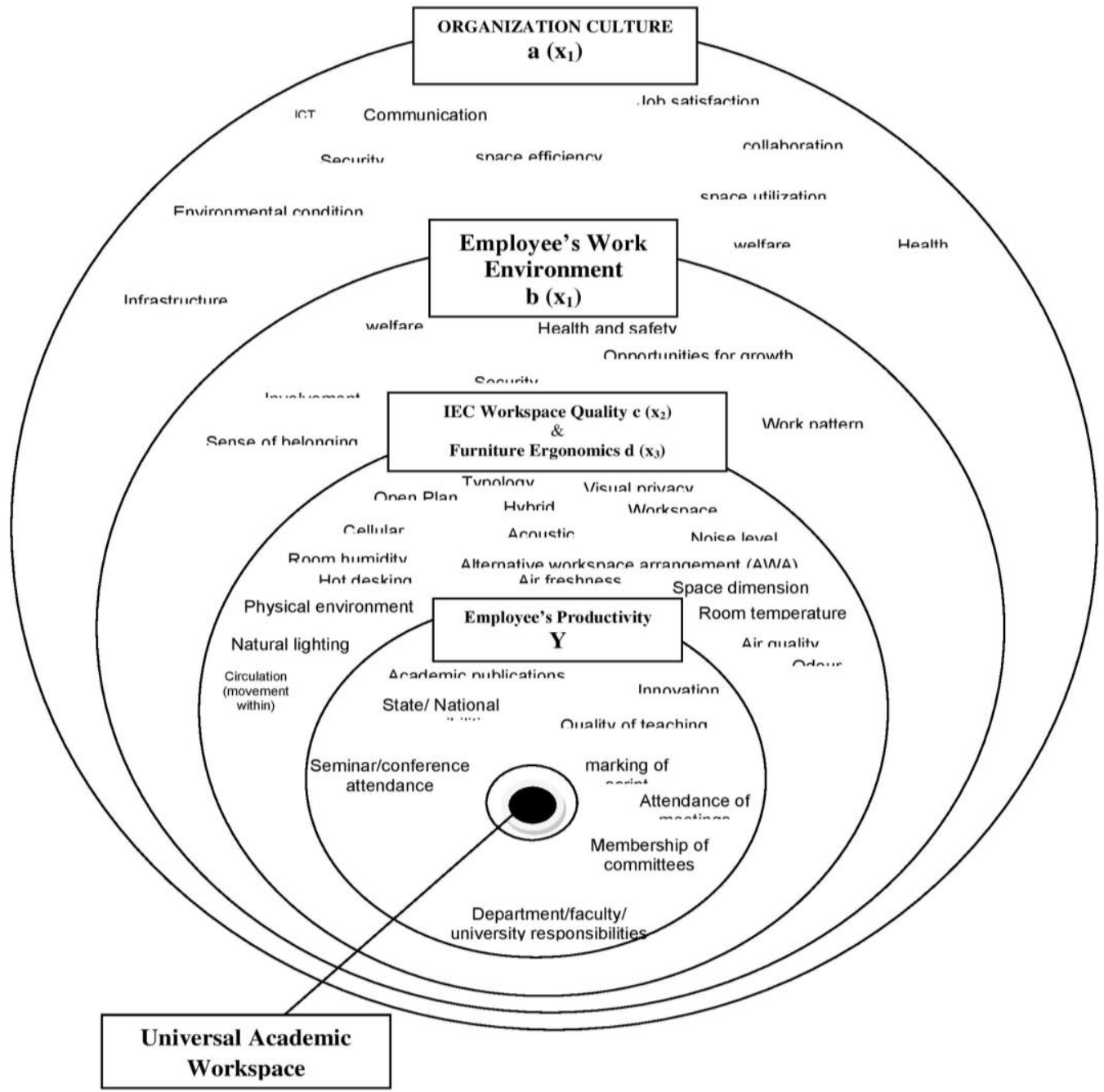

Fig.1: Concentric activities' areas verifying the adequacy of university environment.

Source: Author's conceptual view 
Discussing the context of the opinions stated above, [61] [49] [47] in different independent studies, conclude at different occasions that the way office is designed impacts performance, use of internal environmental decorations, motivation to employees, and job satisfaction. Similarly, [51] and [14] in separate studies linked the importance of work environment to effectiveness, performance and productivity at work.

Work environment is therefore associated with institutional culture. This defines the methodology of communication, behavioural attitude, manner of dressing, status, hierarchy and allocation of space according to status to promote effective coordination of task performance, eliminates employees' stress, promote comfort/emotion, welfare and other packages such as security of employment, compensation for occupational hazards, and reward for professional breakthrough [48] [13].

Study has shown that space occupied by an organisation tells more about its culture and values. This reflects in the cadres, status, promotion, and hierarchy pattern which typifies and determines type of office design in organisations [65]. According to [30] and [75], design of space contributed about $24 \%$ to job satisfaction, $5 \%$ to improved productivity, $11 \%$ increase in team performance, individual productivity by $19 \%$ and organisation productivity by $17 \%$. However, [20] had a different view; considers thermal exposure and vibration causes irritation and therefore negatively impacts workers effectiveness. [22] confirms that if workers get opportunity of protection from risk, allowed to take initiatives, participate in decision making, are time conscious, build trust and transparency among co-workers, and allowed constructive feedback in organisation, such would experience increase in productivity.

[77], discovered the Quality of Work Life (QWL) is a strong determinant of Quality of Life (QoL) because it reflects the workers' perception of organization's corporate identity assessment [75].

For workspace environment assessment to be adequate, it would look beyond the physical comfort alone but also at the comfort compatibility of the office furniture to users [12]. Michigan State University (MSU) referred to this as ergonomic and defines it as the scientific discipline that deals with human interactions and other elements of a system. Furniture ergonomics is the relationship that exists between tool, equipment, and the office as the extension of the user [73]. Office furniture impacts employee's effectiveness and defines user friendliness with shelves, cloaks, interior decorations, chairs, tables, drawers, notice boards, reduces risk of injury and possibility of accidents in the environment [64] [45] [20] [58]. According to [25], suitably designed workspace furniture provides more legroom, adequate support to the elbows and better accessories for users. Opinion generated from different studies [84] [46] indicate that arrangement of furniture for indoor movement inflict stress and friction when workspace is clustered and affects ingress, egress, and proneness to accident. Lighting problem from glares, artificial or natural sources, proximity to windows and the desire to see beyond room scenes by workers, noise and other elements tagged stressors also impact on workers effectiveness.

The academic work environment setting derives from global work environment. However, it assumes distinct form and structure for its specializations. Therefore, it keeps changing over time considering its different policy changes to goals and objectives of education over time. The specific mandate of universities to produce high level manpower, fulfil missions of teaching, research and other services with the expectation to contribute to the development of society in areas of providing increasing access to higher education, local economic impact and social inclusion contributes to uniqueness of university environment [1]. For this purpose, a distinct academic community became imperative. [90] defines academic offices as strange places and the academic a strange people. Workloads associated with academic activities carries different intensity of job timelines to accomplish. This constitute teaching, research, administration, community services, reading, examination supervision, marking, working on computer, paper work, attending to telephone, meeting people, mentoring, guidance and counselling, site visitation, project supervision and practical assessment [37]. Interrelationship is required among the various sectors of the academic community for corporate achievement of objectives. The community so operates as one work environment managed and controlled specifically to achieve a common goal. Policies that established each university, therefore, impacts dynamism, the pattern of growth and development of learning generally.

Study by [33], discovered new method of imparting knowledge from a paradigm shift in approach to learning caused by discovery of ICT. This is seen to have challenged the response of university to its immediate community. Teacher focus learning approach of the past is replaced with student-focus learning approach. Students are now taught to apply their initiatives for self-development; a shift from "instruction paradigm" to "learning paradigm." Similarly, education has changed the emphasis on factual knowledge to ability to think critically and solve complex problems. The impact of this on academic work environment is the change to the horizon of universities and a shift in learning environment to a new learning environment matrix [33]. Innovation has now caused system of economy to be knowledge-driven thereby expanded demand for professionally qualified workers [67]. Because of this, academic work environment with infrastructure is recently designed for team work and collaboration instead of the former personal needs. Space use in academics is now designed to be less specialized, without barriers and boundaries, but with benefits of expanded working hours. [34], concluded that the objective of space provision in the new academic space model is primarily to focus on how to enhance quality of life to support the learning experience. The implication of graduating student from schools with facilities less than adequate, is the direct impact on the competence of the graduate and effectiveness as worker [50] [4]. The idea behind new innovations in academic work environment design is to increase average size of workspace, offices and desks footprints, eliminate 


\section{Towards an Adequate Framework for Academic Workspace Evaluation: How Academics are affected by Environments for Work}

solo offices and possibly to encourage alternative work arrangement (AWA), hoteling for mobile staff, and no staff owns a permanent office [36] [68] [43] [52] [33] [56] [26] [30] [81]. Innovation addresses issues of conflicting interest in academic workspace demands for open plan, enclosed office layouts, flexible workspaces, collaborative workspace, collaboration-concentration workspace, acoustical comfort finish, hoteling, and hot-desking. According to [87], shaping the work experience in recent time depends on how adaptable the design of work environment is.

Contemporary time academic workspace models considers the physical internal environmental factors like noise, temperature and humidity, adequate work area, good ventilation, unobstructed flow of fresh air, free movement within workspace, undisturbed entry and exits, provision of toilet and convenience facilities, sanitary facilities, rest and changing rooms, non-slippery floor finishes and other safety measure that ensures good health, effectiveness, comfortable and home-like work conditions as very important in ensuring user's comfort in the design of workspace [35] [40] [80] [46]. According to [15], to achieve the best sound design considerations in the layout of office is to maximise spacing between people (one of the COVID19 requirements), minimise "lines of sight" between people, separate noisy activities from quiet ones, avoid flat lighting fixture lenses whether in the ceiling, ambient or indirect lighting, instead, allow fixtures with deep parabolic diffusion lenses. By doing this will help to create the most functional acoustical environment in office space.

Health and safety are important to organizations because effectiveness and productivity can only be achieved from healthy and sound minded worker. On the part of employees, the greater part of their functional and social lives is spent in the work environment. When workers waste time and energy because of poor design, the impact is always negative on workers' behaviour [78]. However, some studies have shown positive effects on workers morale, well-being, emotional health and productivity even while workers operate in inadequate workspace conditions [77]. Never the less, some studies [16] [62] [42] [39], recommends that provisions be made to ensure effectiveness at work where workspace environmental factors require Visual Display Unit (VDU). Design of such workspace is usually specific to worker's sitting position and placement of keyboard, the body configuration of the operator, the office furniture, ergonomic specification of the furniture and other ICT accessories [38]. Similarly, design of academic workspace must be related to the amount of space, lighting, reflections, glare, radiation, and software requirements for optimum operation so that an ambient environment is sustained [71] [2]. [11], emphasized further that healthy work environment, safety in workplace, work breaks from screen work and regular conduct of eye tests be ensured.

[66] looked beyond space design and focused more on providing variety of workspaces to support different work styles; link the conventional thought of balance in the HEI with the new approach to academic work environment practices. However, the opinion of the author is that HEI is always determinant amidst traditional practices. Notwithstanding, commercial work environment practices was adopted for the commercialization and globalization of research discoveries. Higher demand for variety of spaces for use developed from challenges of adequacy, flexibility, sustainability, privacy, autonomy, equity, personalization, comfort, and minimum interruption. [66], opined changes that occurred in demand for adjustment to academic needs for space is influenced by internal and external environmental causes. For example, adjustment to use of spaces like seminar rooms is significant to set target to attain required effective space efficiency. A schematic diagram Fig. 2 of the framework indicates the connectivity of the basic environments in universities and how it affects job performance for academics.

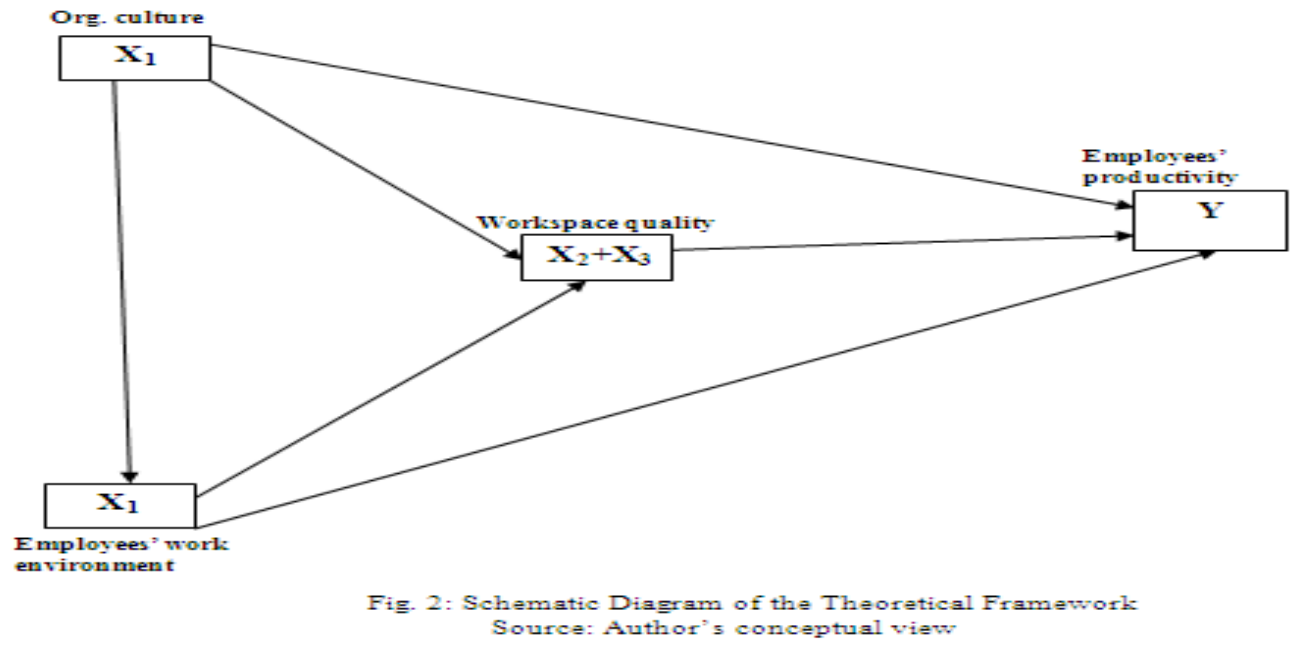

\section{THEORETICAL FRAMEWORK}

This section outlines the various theories underlining the thought of the author. The conceptualized thought is based on the following theories: (i) Theory of organizational culture and employee productivity

(ii) Theory of healthy work environment and employee well-being

(iii) Theory of workspace comfort

(iv) Theory of knowledge-based work in the changing 
world of work.

A. Theory of Organizational Culture and the Employee Productivity

The theory of organization considers approaches to organizational analysis and management. Some of the approaches are the rational system perspective, division of labour, bureaucratic theory and contingency theory. The rational organization system looks at two significant parts; the specificity of goals and formalization. The division of labour theory specifically dwells on the specialization of individual labour roles with respect to increasing performance and productivity in the organization. The contingency theory advocates for maximization of performance by minimizing the effects of varying environmental and internal constraints in the organization. The Human Relations (HR) School of Thought affirms that human or social element operates in the work environment, hence, as productivity increases as much as group dynamics, managerial demands and physical factors also increases. In other word consideration must be to social factors as to financial motivation for workers 'productivity [72].

Culture in organization consists of values and behaviours that contributes to the unique and psychological environment of a business organization. This culture influences interaction between workers, creation of knowledge, resistance to changes and the way workers share knowledge. It represents the collective beliefs of members of the organization and as well are influenced by product, technology, strategy, type of employees, management style; and vision, values, norms, systems, location and habits [63] [59]. Academic institutions like any other organizations would exhibit all these traits for optimal productivity.

B. Theory of Healthy Work Environment and the Employee Well-being

The theory of healthy work environment is based on skilled communication, true collaboration, effective decision making, appropriate staffing, meaningful recognition and authentic leadership. Healthy workplace is associated with legal and professional responsibility to provide employees with a work environment free from recognized hazards that are likely to cause serious physical injury or death, and to maintain working conditions that are safe and healthful for employees [44]. A direct linkage was discovered to exist between organizational functioning and employee well-being socially to balance the psychological aspect of healthy work environment [9].

\section{Theory of Workspace Comfort}

The theory of workspace comfort encompasses the space user's experience of ambient environmental conditions, ergonomics, functional comfort, furniture, health and safety, office layout, productivity, territoriality, satisfaction of the office [74]. However, negative experience from these is associated with work environment stress usually assessed through psychosocial dimension of the work environment such as the relationship between the employee and the employer with respect to motivation and advancement [73]. Workspace stress impacts effectiveness, performance and productivity at work. There are three dimensions to the theory of workspace comfort: the physical comfort that employee experience through the quality of physical environmental conditions of the office space; the psychological comfort relates to the feelings of employee using the psychosocial parameters. According to [73], the psychological comfort is measured using the psychosocial aspects with the physical environmental conditions used in the management of workspace, through the concepts of territoriality, privacy and control. The third dimension is the functional comfort that situates between the basic requirements of the physical comfort and the opportunities for increasing psychosocial comfort. Functional comfort tells how effective workspace is in enabling employees perform their duties rather than how satisfied they are.

D. Theory of Knowledge-based work and the Changing World of Work

Increasingly changing world of work testifies to the impact of new network technologies (ICT) on workspace designs. Knowledge-based work in academics has widen in scope and expectation to adjust with the present time definition of academic. With the scope expanded, activities in knowledge-based work turns fluid in nature that it takes careful observation to draw distinct lines of boundaries between them. Knowledge work modes have apparently cyclically revolving within focused work, collaborative activities, learning and socializing [30]. Majority of knowledge-work that people carried out in this regard consists of intangible work materials with the output also intangibly executed in a wide range of locations many times outside the primary workspace [31]. According to [23] [32] [18] [28], new technology has redefined space requirement, location and time of work. Even in academic, the learning environment matrix is affected and has given rise to the idea of virtual workspace setting. Time/Place/Technology interface grid has developed from changes in the philosophies behind design typologies over time. Models have similarly emerged indicating the impact of technology on choice of workspace demand in recent time. Consequently, explanation for the proposed conceptual model is based on the theories above and is structured for discussion as follows:

a. The organizational culture environment

b. The employee's work environment

c. The academic workspace environment

Figures 1 and 2 present a panoramic view of the AWE environments.

\section{CONCEPT OF ORGANIZATION CULTURE ENVIRONMENT IN ACADEMICS $\left(\mathrm{AX}_{1}\right)$}

According to [75], organizational environment displays three overlapping contextual concepts; (i) the social (ii) the corporate culture and (iii) the virtual environments. These three manifests generally in enterprises whether public, private, academic or non-academic. The social environment focuses on employee interactions, social support networks, social norms, socialization and expectation among group members that dictates behaviours, relationship and space allocation in organization. The organization culture looks at the structure of management decision making style fashioned either hierarchically or in autonomous style, employer-employee relationship, staff behavioural pattern as 
individuals or as a group, space and location identity of organization, and the employee hierarchical spatial allocation giving rise to issues of privacy and confidentiality. This according to [29] has produced a significant impact on Human Resource (HR) policy integration in organizational knowledge. The virtual environment is profoundly indicative in academic environment than in other types of organization setting. Virtual learning is increasingly made possible with positive impacts of ICT tools on globalization of ideas, knowledge, and professional teams from diverse disciplines and time zones [41]. According to [75], consideration of organization culture in the contemporary time goes beyond issues of employee-organization relationship and extends to

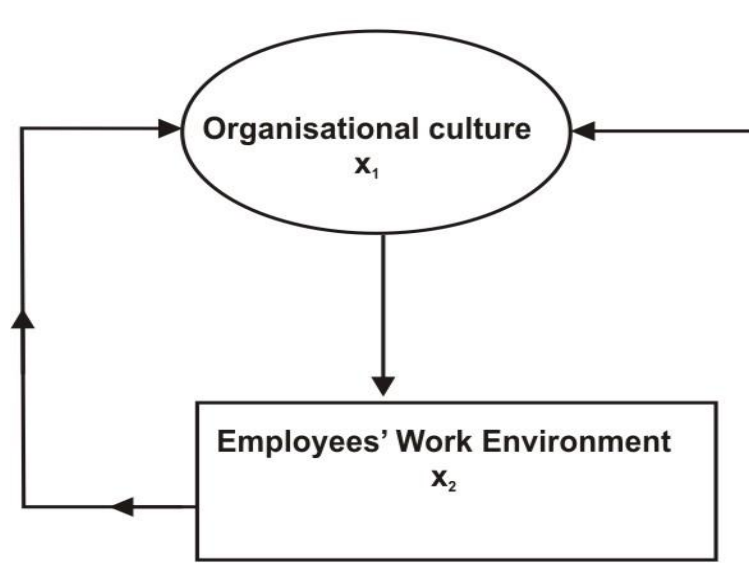

issues of organization-accommodation relationship with focus on rise of networking in organization and emergent knowledge economy in relation to corporate views of human capital that requires knowledge creation and sharing for effective performance. The concept of employee-organization and organization-accommodation was developed into a 'Four Stage' Socialization, Externalization, Combination, and Internalization (SECI) knowledge generating cycle [79] [3]. This has reshaped the organisations' views on work environment and workspace designs.

Fig 3: Impact of Organizational culture on Employees' work environment and the feedback system

Source: Adapted from [89]

According to [66], organizational variables required to determine effectiveness of academic organization constitute job satisfaction, construction costs, churn costs, collaboration, sustainability, flexibility, communication, productivity, space efficiency, space utilization, collegiality, environmental control, health, security, and storage space. The achievement of (a) in the framework requires the enforcement of effective work environment (b) for workers [20]. Other organizational culture variables identified suitable for academic workspace evaluation in this context include: (i) use of performance management process for goal setting (ii) feedback to assess employee's performance (iii) consideration of employee's suitability for assigned responsibilities or workloads (iv) employees' variability to due process (v) opportunity of employee getting supervisor's support (vi) provision of training/mentoring/coaching to update employees skills and performance at work (vii) opportunity to apply newly acquired skills in their jobs (viii) employees motivation to boost commitment to work (ix) provision of job aid (use of templates, guides, models or check list) to make work easier for workers and to minimize error rates $(\mathrm{x})$ workplace attention to general environmental condition (overcrowding, office layout, hygiene, aesthetics, ventilation, air quality, etc.) (xi) communication pattern amongst employees and between employee and authority (xii) use of hierarchy in routine administration or team work (xiii) use of dress code (xiv) allocation of workspace per employee (xv) existence of working pattern for workplace (xvi) workplace consideration of employee behavioural pattern (xvii) rate of office politics or gossip in the workplace (xviii) management approach in handling/managing/settling disputes within workplace (xix) workplace encouragement to promote staff interest in innovation and experimentation (xx) workplace interest in promoting team work (collaboration) between departments, schools, faculties, external bodies or institutions. (xxi) Allow employees take initiatives on their own (xxii) workplace seriousness in area of documentation (xxiii) workplace in area of efficiency (quality of doing things well without waste of time or money) (xxiv) workplace in area of effectiveness (ability to produce result that is wanted or intended promptly) (xxv) presence of criticism among employees in the workplace. The operation of these variables is considerably based on the perception of respondents. The equation developed for the measurement is:

$$
M_{E I}=\frac{\sum_{i=1}^{N} k i}{N}
$$

where:

$M E I i$ is the mean impact indices for performance attribute $i$; $k i$ is the impact rating for attributes $i ; N$ is the total number of respondents; $i$ in this formula is organisation culture.

\section{CONCEPT OF EMPLOYEES' WORK ENVIRONMENT $\left(\mathrm{BX}_{1}\right)$}

[18] studied the increasing changing world of work induced by new network technologies and has provided 
reasons for increasing globalization of industries. For examining the relationship between Organizations, Buildings and Information Technology (ORBIT), studies into the new ways of working was imperative. From these studies, ORBIT organization classification model was invented. ORBIT model discovered that there is no static relationship between the organisation, buildings as the enabling structure and the innovation changing IT. The latter impacts work modes and styles beyond the control of the organisation. The variability of work in the model is defined by the extent to which the organization's goals are routine/predictable or varied/unpredictable. According to the author, the more non-routine the work in the organisation, the more likely the organization is to need the integration of different forms of expertise; increase networking and the more personal meetings would be contemplated. Academic and research works fall within this category to some extent and are more unpredictable and non-routine by nature due to changes technology impact have on them. The learning environment is therefore highly volatile with its knowledge-based activities going fluid [53] [54]. [30] on Workplace Performance Index (WPI) of firms and industries in the USA discovered that knowledge work modes cyclically evolve

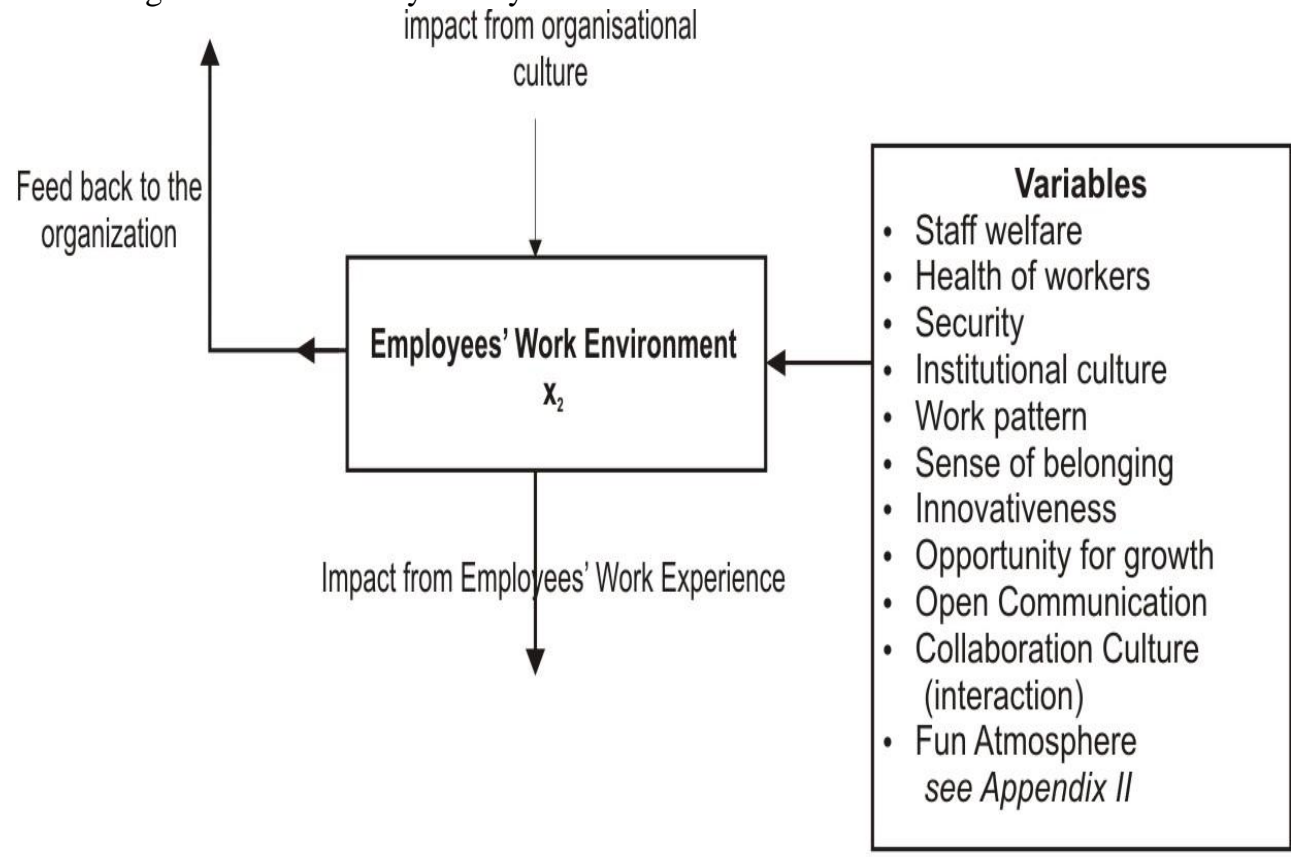

Fig 4: Impact of Employees' Work Environment on the condition of workspace and the feedback system

Source: Adapted from [89]

For reasons of workers interaction, collaboration, (interaction) (xi) fun atmosphere. The equation generated for collegiality and sense of belonging, factors for assessment of effective work environment is in-exhaustive but could be derived from the following variables: welfare, health, safety, work pattern (that is, peculiar way of carrying out work in an organization), security, innovativeness, sense of belonging, opportunity for growth, open communication, collaboration culture (that is, culture of interaction), and fun atmosphere [9] [57]. Employees' work environment variables identified suitable for AWE include: (i) staff welfare (ii) health and safety (iii) security (iv) institutional culture (v) work pattern (vi) sense of belonging (vii) innovativeness (viii) opportunity for growth (ix) open communication (x) collaboration culture round interrelated activities of focusing, collaboration, learning and socializing. Because of the variability of knowledge-based academic work, it has become a challenge to predict future work environment in many organizations. [30], opined that a future workplace will balance spaces for un-interrupted focus work, involve in informal, formal and virtual collaboration and a place where learning will take place in a formal group, or in individually directed or where passive observation would flourish leading to abundant socializing. According to [56], relevance of new technologies is driven by the ability of humans to communicate and collaborate with one another across space and time. In other word, if humans cannot communicate, they would not be able to collaborate. The ability to communicate and collaborate had a profound impact on the use of academic workspace. The academic workspace in this regard would derive its power to be suitable and effectively positioned to encourage individual workers' output towards organisational productivity and goal achievement. In this case, the relationship between $\left(x_{1}\right)$ and $\left(x_{2}\right)$ is determinant and provides an overbearing effect on the workspace condition $\left(\mathrm{x}_{3}\right)$. 
Towards an Adequate Framework for Academic Workspace Evaluation: How Academics are affected by Environments for Work

\section{CONCEPT OF WORKSPACE COMFORT $\left(\mathrm{X}_{2}\right)+\left(\mathrm{X}_{3}\right)$}

According to [89], the bedrock of functionally suitable and effective workspace is its ability to provide maximum comfort for users' optimum productivity. [74] explores the relationship between building exterior space and the interior space prerequisites for goal achievements. These prerequisites are basically environmental factors that determine level and extent of comfort in a workspace. According to [73], comfort provides the basis for setting environmental standards in building to assure healthy and safety of users in the conduct of their activities. Environmental comfort is discerned in three hierarchically related categories. The physical, functional and psychological categories and were expressed as 'environmental comfort model'. The author presented standardized survey study of workspace to determine levels of comfort suitable for workers. The study discovered existence of tripartite relationship among the three categories.

The various changes experienced in academic workspace were attributed to several factors. Firstly, technology had greatly induced the rate at which the world of work will continue to change. This impacts positively on suitability and effectiveness of academic workspaces in the workforce. Secondly, research into adequacy, economy, effectiveness, efficiency and productivity of academic workspace environment will continue to shift as exigencies in areas of ICT, changing work pattern and interrelated academic work modes continue to change in future. This issue is addressed in the next subsection that follows. The subsection proposes a framework for academic workspace evaluation looking at the enabling environmental factors for standardization of global academic workspace for international academic work collaboration. 


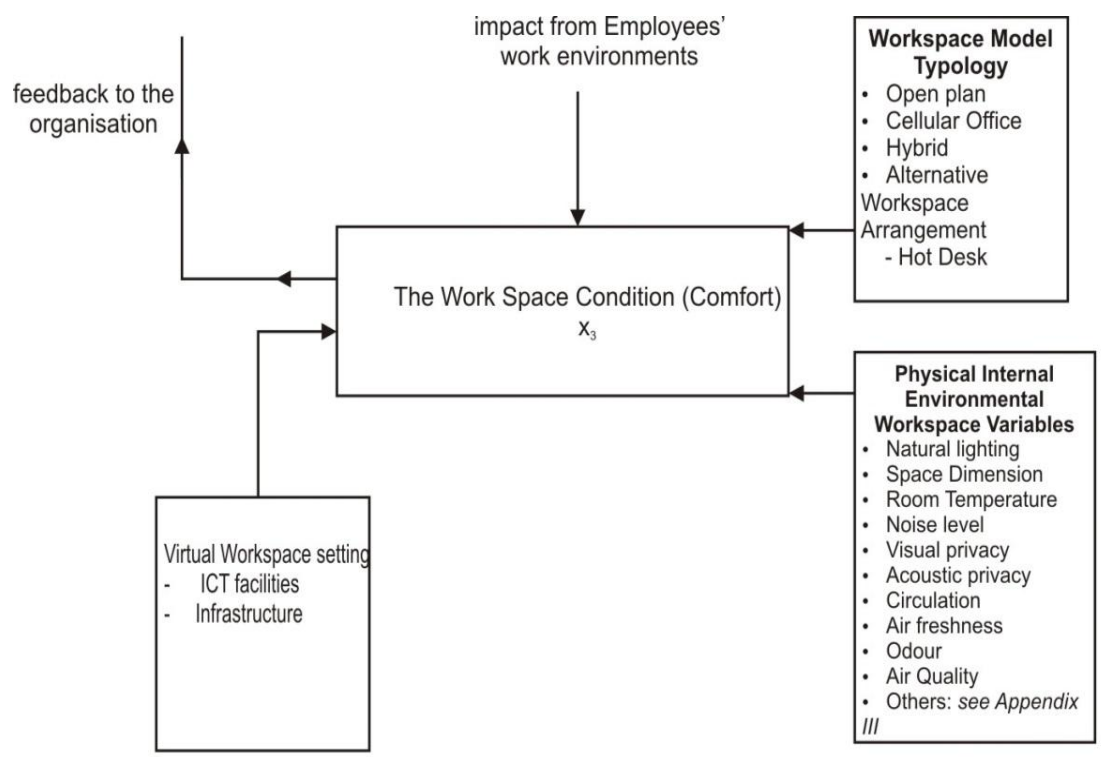

Fig 5: The Impact of both organizational culture and the condition of employees' work environment on the level of comfort provided in the workspace and the feedback system

Source: Adapted from [89]

The following workspace condition variables are found to be intricately associated with quality of effective academic workspace and are therefore required for its evaluation; they include: (i) academic workspace attributes of environmental dimension: natural lighting quality, space dimension, room temperature, noise level, visual privacy, acoustic privacy, room humidity, room ventilation, circulation within room space, air freshness, air quality, odour, electric lighting comfort, floor surface safety, interior beauty, and location of room space. (ii) type of academic workspace design model in use: open-plan; cellular office; hybrid or diverse hybrid (collaborative workspaces: bullpen or pod, informal teaming spaces, non-territorial, high mobility office, radical collocation project room, and extreme collaboration project room); enclosed space plan; and AWA, hot-desking, hoteling, group rooms, shared space (shared work area), work point, workstation; and provision of virtual workspace setting like the virtual desktop, mobile technology, ubiquitous broadband, networked printing, journal publishing, eBook publishing, and website that provides 24/7 services referred to as the Corporate Real Estate (CRE) portal technology (Devine, 2003). The equation developed for the measurement is:

$$
M E I_{m}=\frac{\sum_{m=1}^{N} k m}{N} \cdots
$$

where:

MEIm is the mean impact for performance attribute $m ; \mathrm{km}$ is the impact rating for attributes $m ; N$ is the total number of respondents; $m$ in this equation is the physical internal environmental condition of workspace.

\section{ACADEMIC STAFF PERFORMANCE/PRODUCTIVITY MEASURES (Y)}

The main target of providing the most sustainable work environment in organisation is to boost staff performance and increase corporate productivity. Assessments of independent variables $\mathrm{x}_{1}, \mathrm{x}_{2}, \mathrm{x}_{3}$ is not fulfilling until the value of dependent variable $\mathrm{Y}$ is found to be at the highest standardised value score. If $\mathrm{Y}$ value fall below standardised maximum value, it means that, the contributions of $\mathrm{x}_{1}, \mathrm{x}_{2}, \mathrm{x}_{3}$ is not effective to provide the required enabling environments to allow effective staff performance and productivity. The equation developed for the measurement:

$$
\operatorname{MEI}(y)=\frac{\sum_{(y)=1}^{N} k(y)}{N}
$$

where:

$\operatorname{MEI}(y)$ is the mean effectiveness indices for performance attribute $(y) ; k(y)$ is effectiveness rating for attributes $(y) ; N$ is the total number of respondents; $(y)$ in this equation is the staff performance.

\section{CASE FOR HOLISTICALLY ADEQUATE FRAMEWORK FOR ACADEMIC WORKSPACE EVALUATION (AWE)}

As pointed out by [89], the inputs for a suitably effective and workable academic workspace evaluation structure is numerous and enormous, nevertheless, the operational benefits are sacrosanct [19]. Fig. 6 provides the overview of the connectivity of the entire university environments, elucidates matters of great importance in achieving objectives of HEIs. It further emphasizes the evolution and generation of the working variables of this research. 


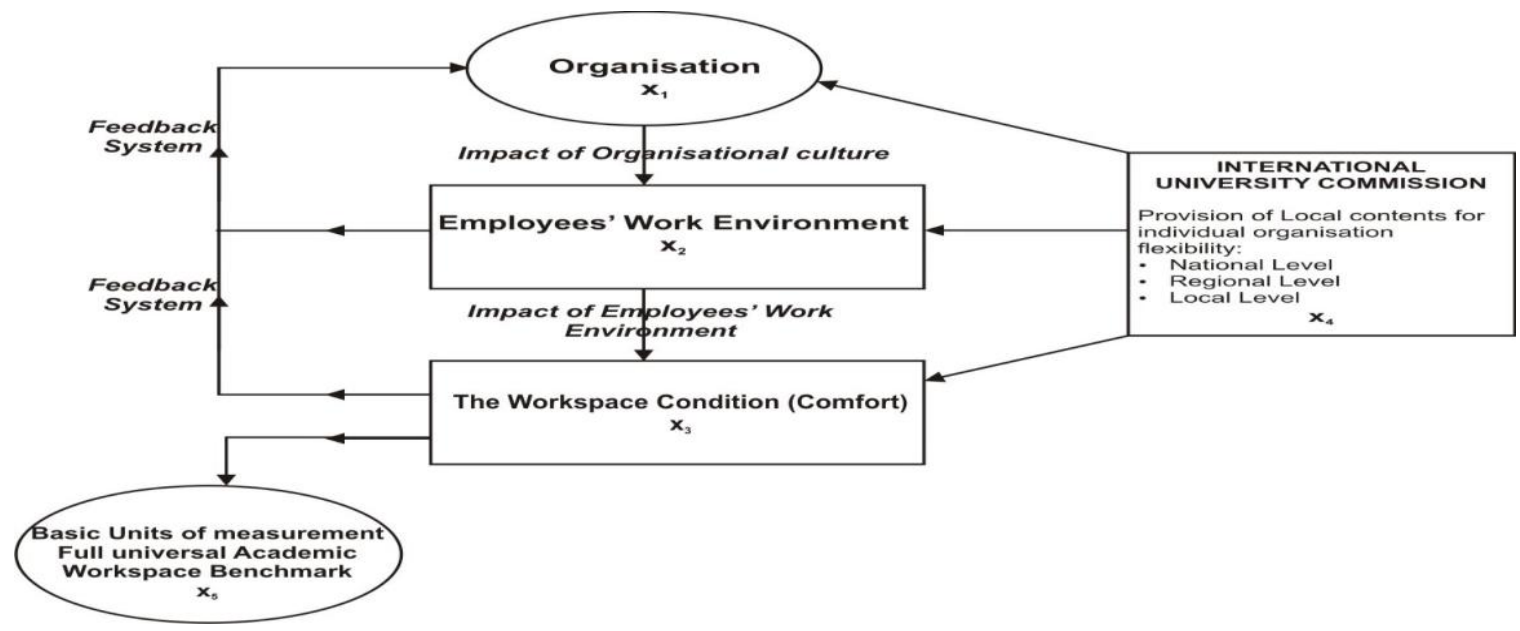

Fig.6: The structure of AWE framework indicating the articulation and connectivity of variables used as basic units of measurement.

Source: Adapted from [89]

The Model Specification for the framework is set as follows:

$\mathrm{Y}=\int\left(\mathrm{x}_{1}, \mathrm{x}_{2}, \mathrm{x}_{3}\right)$

Where:

Y=Academic workspace performance (assessment based on staff performance/productivity)

$\int=$ function of

$\mathrm{X}_{1}=$ Organizational culture environment

$\mathrm{X}_{2}=$ Employees' work environmen

$\mathrm{X} 3=$ The workspace conditions

Universal workspace benchmark is imperative in contemporary time to set standard for adequate and effective space use of tomorrow in academics, accommodate basic modes of academic work setting and to enable 'feel-at-home' collaborations anywhere in the world [89]. As academic has become professionalized, internationalized and highly entrepreneurial [43], management of academic facilities should advance toward distinct specialization within the global framework of facilities management.

\section{CONCLUSION}

This study indicates a gap in academic workspace standards globally. Implication of inadequacy in this area is more in developing countries than in developed countries. The proposed framework has initiated efforts in articulating cognately suitable variables for AWE and assessment. The study also demonstrates the operation of the variables to achieve results. Provision is made to insert local contents in the framework to give room for individual organisational flexibility in operation. Looking at the rate technological change impact teaching and learning in HEIs in recent times, further research is required on reviews of established standards to keep the trends in the changing world of academic environment.

Finally, as academic workspace is unique and occupies a special place in the physical and environmental facilities of universities, setting up minimum standard would encourage stakeholders in provision of academic workspace facilities to be more guided and encouraged by ensuring laudable designs for academic workspace. Standardised AWE framework could also help to maintain academic leverage between developing and developed countries of the world.

\section{REFERENCES}

[1] Abdulkareem, A. Y., Fasasi, Y. A., and O. P. Akinnubi, Human Resource Utilization and Internal Efficiency in StateOwned Universities in Nigeria. International Journal of Academic Research in Business and Social Sciences, 2011,1(1), 26-34.

[2] Abisuga, A.O., Famakin, I.O, and Oshodi, O.S, Educational Building Conditions and the Health of users. Construction Economics and Building, 2016, 16(4), 19-34.

[3] Abisuga, O., Wang, C, and Kamardeen, I, Towards conceptualization of SocioBIM-based post-occupancy evaluation framework for learning spaces. In P.Wu and X.Wang (Eds), Innovative Production and Construction: transforming Construction through Technologies, World Scientific, 2019 , 17-38.

[4] Adedeji, J.A and Fadamiro, J.A, Workplace and Productivity: A Post Occupancy Evaluation of LAUTECH Senate Building, Ogbomoso, Nigeria. Architecture Research, 2012, 3(2): 14-19.

[5] Adeyeye, J.O., Adeniji, A.A., Osinbanjo, A.O. and Oludayo, A.O, Effects of Work environment Ethics on Employees and Organisational Productivity in Nigeria, Proceedings of the 2nd International Conference of African Development. Ota, Nigeria. 2015, 267-273

[6] Ajala, E. M, The Influence of Work environment on Workers' Welfare, Performance and Productivity. The Africa Symposium, 2012, 12(1), 141-149. [7] Ajala, E. M, The Impact of work environment spirituality and employees' wellbeing at the Industrial Sector: The Nigerian Experience. The African Symposium, 2013, 13(2), 3-13.

[8] Alexi Marmot Associates AMA. Reimagining Academic Workspace, Seminar Report, 2013.

[9] American Psychological Association, APA. Psychologically Healthy Work Environment Program, 2008 (http://www.apaexcellence.org)

[10] Amusa, O. I., Iyoro, A. O. and A. F. Olabisi, Work environments and job performance of librarians in the public universities in South-west Nigeria. International Journal of Library and Information Science, 2013, 5(11): 457-461.

[11] Animashaun, O. and Odeku, K. O, An overview of neglected but important factors affecting employee's productivity, health and safety in the work environment. Mediterranean Journal of Social Science, MCSER Publishing. Rome-Italy, 2014a, 5(20), 2967-2975.

[12] Animashaun, O. and Odeku, K. O, Industrial Accident and Safety Hazards at the Work environment: A Spatio-physical Work environment Approach. Mediterranean Journal of Social Sciences, 2014b, 5(20), 2949-2953.

[13] Arokiasamy, A. R. A, Study on employee satisfaction perspectives in the hotel industry in Malaysia. International Journal of Management and Strategy, 2013, 4(6)

[14] Awan, A. G. and Tahir, M. T, Impact of working environment on employee's productivity: A case study of Banks and Insurance Companies in Pakistan. European Journal of Business and Management, 2015, 7(1), 329-345.

[15] Barkman, P. and Walton, E, Office Sound Control Solutions, 2019. http://www.soundmanagementgroup.com

[16] Booty, F, Facilities management handbook. Routledge, New York, USA, 2009 
[17] Briner, R. B, In-depth Review: Relationships between work environments, psychological environments and psychological well-being. Great Britain. Occup. Med. 2000, 50(5), 299-303.

[18] CABE (Commission for Architecture \& the Built Environment), and British Council for Offices. The impact of office design on business performance, 2005a. Retrieved from http:/www.cabe.org.uk and http://www.bco.org.uk

[19] Caramela, S, A Workplace that Works: Designing a Productive Office 2018. Retrieved from http://www.sammysays.org.

[20] Chandrasekar, K, Work environment and its impact on organisational performance in public sector organisations. Alagappa University, Karaikudi, India. International Journal of Enterprise Computing and Business Systems, 2011, (1), 1-20. Retrieved from http://www.ijecbs.com

[21] Devine, B, Asset Management: In Work environment Strategies and Facilities Management, Butterworth-Heinemann, Linacre House, Jordan Hill, Oxford OX2 8DP, 2003.

[22] Dhar, S, and Dhar, P. Consumable Booklet: Organisational Culture Scale, Shri Vaisuau Institute of management, Indorr, India (n.d)..

[23] Duffy, F. and Chandor, M, The Orbit Study-Information Technology and Office Design. DEGW/Eosys. London. 1983.

[24] European Agency for Safety and Health at Work (EU-OSHA, Wellbeing at Work: Creating a positive Work Environment, Literature Review 2013, Retrieved from http://www.eurosfound.europa.eu/publications/htmlfiles/ef1228htm,1-33 [25] Fabrizio, P. Ergonomic intervention in the treatment of a patient with upper extremity and neck pain. Physical Therapy, 2009, 89(4), 351-360.

[26] Fayard, A and Weeks, J. Who moved my Cube? Harvard Business Review, 2011, 103-111. Retrieved from http://www.nbr.org

[27] Fields, B. "DEGW Report, The Impact of Change": Transcription, 2017. PDF_files/saved_resource(10).html.

[28] Fisher, K. Research into Identifying Effective Learning Environments. Evaluating Quality in Educational Facilities OECD/PEB 2005.

[29] Grant, R.M. Toward a Knowledge-based Theory of the Firm. Strategic Management Journal 1996, 17: 109-122.

[30] Gensler What we've learned about focus in the work environment 2012, Retrieved from http:// gensleron.com/work/2012/1/24/focu-on-focus.html [31] Gilmore, D. "Holistic Ergonomics for the Evolving Nature of Work," Transcription 2017, PDF_files/saved_resource(10).html.

[32] Harbinger Group Orbit2 - Executive Overview, Harbinger Group, Norwalk, CT, 1985.

[33] Harrison, A., and Cairns, A, The Changing Academic Work environment, DEGW, UK Ltd. 2008

[34] Harrison, A. and Dugdale, S. The SANE Research Project: Its Implications for Higher Education. Planning for Higher Education, 2003, 3341.

[35] Hart, S. H. Self-regulation, Corporate Social Responsibility and the Business Case: Do they Work in Achieving Work environment Equality and Safety? Journal of Business Ethics, 2010, 92(4), 585-600.

[36] Heerwagen. J. H., Kampschroer, K., Powell, K. M, and Loftness, V. Collaborative Knowledge Work Environment. In Building Research and Information, Span Press, 2014, 32(16), 510-528. Retrieved from https://wwwresearchgate.net/publication/240803011.

[37] Higher Education Funding Council for England (HEFCE), Effecting Change in Higher Education, 2003. Retrieved from http://www.luton.ac.uk/approaches_to_change/

[38] Howard, G. S, Legal aspects of fitness for work - Fitness for work: The Medical Aspects, Oxford University Press, Oxford, UK, 2013.

[39] Hughes, P, and Ferrett, E. Introduction to health and safety at work, Butterworth Heinemann, Oxford, UK, 2011.

[40] Landoni, P. P. Industrial Site, Work environment Transport and Safety Management, 2012. Retrieved from http://www.aidic.it/cet/12/26/100.pdf.

[41] Langhoff, J. An Overview of Remote Virtual Teams and Productivity. New Ways of Working (NewWOW), 2006. www.newWOW.net

[42] Liedtke, M, Risk by use of hearing protectors: expert program supports SMEs in appropriate selection and use. Noise and Health, 2005, 7(26), 31-37.

[43] Locke, W. The Changing Academic Profession in the UK: Setting the Scene. Universities UK, London, UK, 2007.

[44] Marshelle, T. A safe and Healthy Work Environment: Home care provider, 1996, 1(2), 91-96.

[45] McKeown, C. Office ergonomics: practical applications, 2007. Retrieved from http://books.google.co.za/books.

[46] Mohammad, S., Sapri, M, and Sipan, I, Academic Buildings and Their Influence on Students' Wellbeing in Higher Education Institutions. Social Indicators Research, 2014, 115(3)

[47] Mokaya, S. O. Effect of Organisational Work Conditions on Employees' Job Satisfaction in the Hotel Industry in Kenya. International Journal of Arts and Commerce, 2013, 2(2), 79-90.
[48] Noah, Y, and Steve, M. Work Environment and Job Attitude among Employees in a Nigerian Work Organisation, Journal of Sustainable Society, 2012, 1(2), 36-43.

[49] Obiozo, R. N., Uduma-Olugu, N. and Dimoriaku, I. D. Biophilic design of the workspace: How living buildings and landscapes enhance environmental health and productivity. Seminar paper. Department of Architecture, Enugu State University of Science and Technology (ESUT), Enugu, Enugu State, Nigeria, 2012, 1-9.

[50] Ogunsaju, S. Some Aspects of School Management. Ibadan, 1980.

[51] Ollukkaran, B. A, and Gunaseelan, D. R. A study on the impact of work environment on employee performance. International Journal of Management Research, 2012, 2(2), 71-85.

[52] O'Neill, M, Measuring Work environment Performance. Taylor and Francis, New York, NY, 2007.

[53] O'Neill, M. and Wymer, T, What to consider when shifting from private office to open plan, Knoll research white paper, 2007.

[54] O’Neill, M. and Wymer, T. Design for Integrated Work. White Paper, Knoll, Inc., New York, NY, 2009.

[55] Oyinlola, I.A., Abiodun, O.I. and Ajani, F.O. Work environments and job performance of librarians in the public universities in Southwest Nigeria, academic Journals, 2013, 5(11), 457-461.

[56] Pinder, J., Parkin, J., Austin, S., Duggan, F., Lansdale, M., Demian, P., Baguley, T., and Allenby, S, The Case for New Academic Workspaces, Leicestershire: Department of Civil and Building Engineering, Loughborough University, UK, 2009. Retrieved from www.academicworkspace.comm/content/view/35/48/

[57] Pot, F. Work environment innovation to achieve the EU2020 Strategy: Wellbeing at Work Conference, PEROSH/HSL, Manchester, United Kingdom, 2012.

[58] Rantanen, H. Generational work environment preferences: Case Ovenia, 2013. Retrieved from http://www. thesus.fi/handle/10024/69703 [59] Ravasi, D. and Schultz, M. Responding to Organisational Identity Threats: Exploring the role of organisational culture: Academy of Management Journal, 2006, 49(3), 433-458.

[60] Sajida, P., Malik, M. S., Farheen, N., Zarqa, A., and Saddat, H. K. Impact of Office Facilities and Work environment milieu on Employees' Performance: A case study of Sargodha University. Asian Journal of Empirical Research, 2013, 2(4), 96-117.

[61] Sarah, B. Learning Spaces of Tomorrow, Woods Bagot, Deakin Uni Burwood Highway Frontage Building I, Melbourne, 2012.

[62] Sargent, E.V., and Gallo, F. Use of personal protective equipment for respiratory protection. ILAR Journal, 2003, 44(1), 52-56

[63] Schein, E. H. Organisational culture and leadership $\left(3^{\text {rd }}\right.$ ed.), san Francisco: Jerssey-Bass. 2004, 22-33, ISBN 0787968455.OCLC 54907721

[64] Schriefer, A. E. Work environment strategy: What it is and why you should care, 2005. Retrieved from http://www.emeraldinsight.com/doi/pdfplus/

[65] Sehgal, S. Relationship between Work Environment and Productivity, International Journal Engineering Research and Applications, 1995, 2(4), 1992-1995

[66] Sheahan, M. The Future Academic Workspace: A Literature Review, EcoSciences Precinct, Brisbane, Queensland, Australia, 2014, 1-12.

[67] Space Facilities Committee (SFC), Spaces for learning: a review of learning spaces in further and higher education. UK, 2006.

[68] Space Management Group (SMG), UK Higher Education Space Management Project: Promoting Space Efficiency in Building Design, 2006.

[69] Thomson, A. K. Vehicle movement and loading bay design, 1997.

Retrieved from http://link.springer.com/chapter/

[70] Thompson, K. and Luthans, F. Culture, researchgate.net, 2019.

[71] Toomingas, A., Cohen, P., and Jonsson, C. A Sound Working Environment in Call and Contact Centre, 2006. Retrieved

http://nile.lub.lu.se/arbarch/arb/2006/arb2006_49.pdf.

[72] Van De Ven, A. H., Ganco, M., and Hinnings, C. R. Returning to the Frontier of Contigency Theory of Organisational and Institutional Designs. The Academy of Management Annals, 2013, 7, 393-440, doi:10.1080/19416520.2013.774981.

[73] Vischer, J. C. The effects of the physical environment on job performance: towards a theoretical model of workspace stress. Stress and Health, 2007, 23, 175-184.

[74] Vischer, J. C. Towards a Psychology of the Work environment. In Chapter 3, The Future Office, Taylor and Frances, Oxon, UK. 2008.

[75] Vischer, J. C. Human Capital and the Organisation-Accommodation Relationship: In Handbook of Human Capital, U.K. Oxford University Press. 2010.

[76] Vischer, J.C. The changing meaning of workspace: planning space and technology in the work environment. In Enhancing Building Performance; S. Mallory-Hill, W.F.E.Preiser, C.Watson (Eds). Chichester, U.K.: John Wiley \& Sons, Ltd. 2012. 
Towards an Adequate Framework for Academic Workspace Evaluation: How Academics are affected by Environments for Work

[77] Vischer, J. C. and Wifi, M. The Effect of Work environment Design on Quality of Life at Work: In Handbook of Environmental Psychology and Quality of Life Research. G. Fleury-Bahi., E. Pol., \& O. Navrro. (Eds), London: Springer, 2015.

[78] Vischer, J. C. Building-in-use assessment: Foundation of workspace Psychology: In Chapter 9 Building Performance Evaluation, W. F. E Preiser., A. Hardy., \& U. Schramm (Eds.), Springer Publishing, 2018.

[79] Von Krogh, G., Ichijo, K., \& Nonaka, I. Enabling knowledge creation: How to unlock the mystery of tacit knowledge and release the power of innovation, Oxford, UK: Oxford University Press, 2000.

[80] Walia, R. An analytical study of employees' welfare schemes: a case study of Panipat Thermal Plant, 2013.. Retrieved from http://shodhganga.inflibnet.ac.in/handle/10603/10925

[81] Walsh, J. Knowledge Management: Collaboration versus Concentration in Open Plan Workspaces, Dublin Institute of Technology, DIT, 2015, 3(12).

[82] Williams, L. "Innovative Workplace for Hourly Workers": Transcription, 2017. PDF_files/saved_resource(10).html.

[83] Workspace Overview, Workspace https://dit.ie/media/granggorman/ HEFCE, 2013

[84] Worthington, J. Reinventing the work environment, 2013. Retrieved from http://books.google.co.za/books

[85] Fayard, A. and Weeks, J. Leadership and managing people book: Executive Summary. Reprint. R1107H. 2018.

[86] Adenipekun, M.T., Ajibola, M.O. and Olawunmi, A.O, Effective workspace design: imperative in resolving problem of increasing fluidity of knowledge-based academic activities in universities, JPCS, vol.1299, 2019 [87] Lee, D, Knollwork environment research: Adaptable by design; shaping the work experience. Knoll, Inc. PDF_files/saved_resource (9).html. 2017

[88] Adenipekun, M.T., Ajibola, M.O. and Oluwunmi, A.O, Innovation in academic workspace design: the implication for sustainable effectiveness, IOP Conf. Ser: Earth Environ. Sci.665 01 2026, 2021, doi:10.1088/1755-1315/665/1/012026

[89] Adenipekun, M.T., Ajibola, M.O. and Oluwunmi, A.O, Providing a sustainable framework for academic workspace evaluation: A literature review, ICSSD, Covenant University, Ota, Nigeria. 2020.

[90] Shahidah, B, Workspaces: why academics need a room of their own, Time Higher Education, 2015.

Biography of author

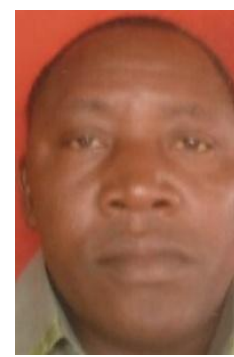

Adenipekun, Tai Martins: HOD, Principal Lecturer Education Background: (i) HND Estate Management; The Polytechnic Ibadan; 1981-1986

(ii) Master of Urban \& Regional Planning; University of Ibadan; 1995-1998

(iii) M.Tech. Estate Management; Federal University of Technology Akure 2010-2014

(iv) $\mathrm{PhD}$ Estate Management (in view)

Work Experience: 10 years of practical and 22 years of teaching and research experience.

Current and previous research interests: Real Estate Planning \& Management; Property Valuation; Real Estate Investment Appraisal; Urban \& Regional Planning; and Academic Workspace Facilities Management.

Membership of professional societies and award received:

(i) Associate Member of Nigerian Institution of Estate Surveyors \& Valuers (ANIVS).

(ii) Registered Estate Surveyor \& Valuer by Estate Surveyors and Valuers Registration Board of Nigeria (ESVRBON). 